\title{
Effect of drying method on mechanical, thermal and water absorption properties of enzymatically crosslinked gelatin hydrogels
}

\author{
RAYSSA C. SIMONI ${ }^{1}$, GISLAINE F. LEMES ${ }^{2}$, SANDRA FIALHO ${ }^{1}$, ODINEI H. GONÇALVES ${ }^{2}$, ANGELA M. \\ GOZZO $^{1}$, VIVIANE CHIARADIA ${ }^{3}$, CLAUDIA SAYER ${ }^{3}$, MARIANNE A. SHIRAI ${ }^{2}$ and FERNANDA V. LEIMANN ${ }^{2}$ \\ ${ }^{1}$ Departamento Acadêmico de Alimentos/DALIM, Universidade Tecnológica Federal do Paraná, Campus Campo Mourão/ \\ UTFPR-CM, Via Rosalina Maria dos Santos, 1233, Caixa Postal 271, 87301-899 Campo Mourão, PR, Brazil \\ ${ }^{2}$ Programa de Pós-Graduação em Tecnologia de Alimentos/PPGTA, Universidade Tecnológica Federal do Paraná, Campus \\ Campo Mourão/UTFPR-CM, Via Rosalina Maria dos Santos, 1233, Caixa Postal 271, 87301-899 Campo Mourão, PR, Brazil \\ ${ }^{3}$ Departamento de Engenharia Química e Engenharia de Alimentos, Universidade Federal de Santa Catarina, Centro \\ Tecnológico/CTC, Campus Reitor João David Ferreira Lima, Caixa Postal 476, 88040-970 Florianópolis, SC, Brazil
}

Manuscript received on April 28, 2016; accepted for publication on January 23, 2017

\begin{abstract}
Enzymatically crossliked gelatin hydrogel was submitted to two different drying methods: air drying and freeze drying. The resulting polymeric tridimensional arrangement (compact or porous, respectively) led to different thermal and swelling properties. Significant differences $(p<0.05)$ on thermal and mechanical characteristics as well as swelling in non-enzymatic gastric and intestinal simulated fluids $\left(37^{\circ} \mathrm{C}\right)$ were detected. Water absorption data in such media was modelled according to Higuchi, Korsmeyer-Peppas, and Peppas-Sahlin equations. Freeze dried hydrogel showed Fickian diffusion behavior while air dried hydrogels presented poor adjustment to Higuchi model suggesting the importance of the relaxation mechanism at the beginning of swelling process. It was possible to conclude that the same gelatin hydrogel may be suitable to different applications depending on the drying process used.
\end{abstract}

Key words: air drying, freeze drying, hydrogel, transglutaminase.

\section{INTRODUCTION}

Hydrogels are a promising type of 3-dimensional crosslinked hydrophilic polymeric networks presenting interesting characteristics for biomedical applications since they do not dissolve in water at physiological temperature and $\mathrm{pH}$ conditions (Pal et al. 2007). Food packaging sector may benefit from hydrogels in applications as timetemperature indicators (Pereira Jr et al. 2015), nutraceuticals release in functional foods (McClements et al. 2009), fat replacers (Chung et al. 2014, Manzocco et al. 2013) and rheology control (Shewan and Stokes 2013).

\footnotetext{
Correspondence to: Fernanda Vitória Leimann

E-mail: fernandaleimann@utfpr.edu.br / fevitoria@gmail.com

* Contribution to the centenary of the Brazilian Academy of Sciences.
} 
Gelatin hydrogels synthesis may be achieved by crosslinking with glutaraldehyde (Prata et al. 2008), genipin (Devi and Maji 2010) or transglutaminase (Carvalho and Grosso 2006). Transglutaminase (TGase) is a transferase that forms both inter and intramolecular isopeptide bonds by crosslinking glutamine and lysine residues from (Heidebach et al. 2009).

Gelatin is a protein obtained by the hydrolysis of collagen from animals bones and skin and has been commonly used for pharmaceutical and medical applications because of its biodegradability and biocompatibility in physiological environments (Khan and Schneider 2013). Furthermore, gelatin presents appealing physico-chemical properties such as (i) great capacity for modification at amino acids level, (ii) low immunogenicity and cytotoxicity, (iii) FDA approval as a clotting agent and exudate-absorbing construct, (iv) hydrogel formation by facile, low cost procedures (Einerson et al. 2002).

Although crosslinking extension plays an important role in hydrogels properties, attention must be paid to the drying method since it may lead to modifications on the tridimensional arrangement of the polymeric network during water removal (Wang et al. 2012). Freeze dried hydrogels presents more porous structure altering the release of loaded compounds (Risbud et al. 2000, Shalaby et al. 1991). Porosity must be controlled because it directly affects water uptake and thus the release of active molecules from hydrogels (Díaz-Bandera et al. 2013, Koo et al. 2014).

Production of hydrogels from transglutaminase crosslinked gelatin is well stablished in the literature (Dong et al. 2008, Lim et al. 1999, Prata et al. 2008). However, the effect of the drying method on such hydrogels still needs to be elucidated, mainly in respect of swelling, mechanical and thermal properties. In this work, enzymatically crosslinked gelatin hydrogels with the same composition were dried by freeze drying and conventional oven drying and their properties were investigated, namely the equilibrium of swelling, water absorption mechanism and thermal properties.

\section{MATERIALS AND METHODS}

\section{MATERIAL}

Gelatin and glycerol (Vetec, analytical grade) were used in the hydrogel synthesis. The enzyme transglutaminase (TGase, ACTIVA GM, 110 units/g) was kindly supplied by Ajinomoto Inc. Hydrochloric acid, sodium chloride, monobasic potassium phosphate and dibasic potassium phosphate (Vetec, analytical grade) were used in the preparation of non-enzymatic gastric and intestinal simulated fluids. Potassium bromide (KBr, spectroscopic grade, Sigma-Aldrich) was used in the Fourier Transform Infrared analyses.

\section{HYDROGEL SYNTHESIS AND DRYING}

Hydrogel synthesis was carried out according to Chambi and Grosso ( 2006) with some modifications. First, gelatin $\left(4.2 \mathrm{~g}, 7 \mathrm{~g} / 100 \mathrm{~g}_{\text {water }}\right)$ was dissolved in distilled water $(60 \mathrm{~mL})$ at $50{ }^{\circ} \mathrm{C}$ under magnetic stirring and then glycerol $\left(1.05 \mathrm{~g}, 25 \mathrm{~g} / 100 \mathrm{~g}_{\text {gelatin }}\right)$ was added to the solution. This solution was cooled at $25^{\circ} \mathrm{C}$ and transglutaminase (763 mg or 20 active units $/ \mathrm{g}_{\text {gelatin }}$ ) was added under magnetic stirring. Finally, the resulting solution was poured into a silicone vessel $(4 \times 9 \mathrm{~cm})$ and the crosslinking reaction took place $50{ }^{\circ} \mathrm{C}$ for 15 minutes. After this time, the hydrogels were immediately transferred to an oven and kept at 85 ${ }^{\circ} \mathrm{C}$ for 10 minutes in order to inactivate the enzyme. The obtained hydrogel was dried under two different conditions: (i) air convection oven at $40{ }^{\circ} \mathrm{C}$ for 24 hours; or (ii) freeze-drier (Liotop 101L, Liobras) at -50 
${ }^{\circ} \mathrm{C}$ and $150 \mu \mathrm{mHg}$ for 24 hours followed by freezing at $90{ }^{\circ} \mathrm{C}$ for 5 hours. All samples were kept in a glass desiccator until analyses. The procedures were repeated three times for each experimental condition.

\section{SCANNING ELECTRON MICROSCOPY}

Freeze dried hydrogels (FDH) and air dried hydrogels (ADH) were submitted to Scanning Electron Microscopy (JEOL JSM-6390LV) for morphological observations. Samples were frozen in liquid nitrogen, fractured and gold coated before analyses.

\section{EQUILIBRIUM DEGREE OF SWELLING}

Equilibrium degree of swelling (EDS) was determined according to Wang et al. (2012). The dried samples $\left(3 \times 3 \mathrm{~cm}\right.$ ) were kept in an oven at $40{ }^{\circ} \mathrm{C}$ during $24 \mathrm{~h}$ and then weighted $\left(\mathrm{W}_{0}\right)$. After that, samples were immersed in distilled water $(200 \mathrm{~mL})$ at $25^{\circ} \mathrm{C}$ during $24 \mathrm{~h}$ and weighted $\left(\mathrm{W}_{24}\right)$. The equilibrium degree of swelling in water (EDS) was calculated using Equation (1).

$$
\operatorname{EDS}(\%)=\frac{W_{24}-W_{0}}{W_{0}} \times 100
$$

\section{DYNAMIC SWELLING STUDIES}

To evaluate the influence of the drying treatments on the swelling behavior, FDH and ADH were allowed to swell from the dried state in simulated gastric fluid $\left(\mathrm{pH} 1.2 ; 2 \mathrm{~h}, 37^{\circ} \mathrm{C}\right)$ and subsequently in simulated intestinal fluid ( $\mathrm{pH} \mathrm{7.4;} 4 \mathrm{~h}, 37^{\circ} \mathrm{C}$ ) (Argin et al. 2014). Non enzymatic simulated fluids were prepared according to The United State Pharmacopeia (1999). The hydrogels weight was recorded at timed intervals up to $360 \mathrm{~min}$. Swelling kinetics were determined by the swelling degree at each time interval and calculated using Equation 2, where $\mathrm{W}_{\mathrm{s}}$ is the weight of the swollen hydrogel after a specific swelling time.

$$
\text { Swelling degree }(\%)=\frac{W_{s}-W_{0}}{W_{0}} \times 100
$$

For the water absorption analysis, the swelling ratio (Q) was calculated using Equation 3 and adjusted to the Higuchi, Korsmeyer-Peppas and Peppas-Sahlin equations (Equations 4, 5 and 6, respectively), where $M_{t}$ is the mass of absorbed water at time $t$ and $M_{f}$ represents the absorbed water at an infinite time. Nonlinear least squares fitting method was used to determine the parameters in each equation using Statistica 7.0 software (Statsoft).

$$
\begin{gathered}
Q=\frac{W_{s}}{W_{0}} \\
M_{t} / M_{f}=k^{\prime} t^{1 / 2} \\
M_{t} / M_{f}=k t^{n} \\
M_{t} / M_{f}=k_{d} t^{m}+k_{r} t^{2 m}
\end{gathered}
$$




\section{DIFFERENTIAL SCANNING CALORIMETRY}

Hydrogels thermal properties were determined by Differential Scanning Calorimetry (DSC, Perkin Elmer, DSC 4000) calibrated with indium and zinc standards. Samples (approximately $10 \mathrm{mg}$ ) previously conditioned at $25{ }^{\circ} \mathrm{C}$ for 2 weeks in desiccator) were placed in aluminum pans and then heated at 20 ${ }^{\circ} \mathrm{C} \cdot \mathrm{min}^{-1}$ from 0 to $250{ }^{\circ} \mathrm{C}$ under gaseous nitrogen $\left(20 \mathrm{~mL} \cdot \mathrm{min}^{-1}\right)$. Glass transition temperatures (Tg) were determined as the point of inflexion in the base line caused by the discontinuity of samples specific heat capacity. Melting temperature (Tm) was recorded as the onset temperature of the endothermic peak (Farris et al. 2011).

\section{PUNCTURE TEST}

Hydrogels puncture strength and puncture deformation were determined by the puncture test at a TA.XT Express Enhanced texturometer (Stable Micro Systems). Hydrogels were cut in circular samples (diameter $1_{0}=30 \mathrm{~mm}$ ) after swollen for $24 \mathrm{~h}$ (see EDS determination). After that, hydrogels were fixed in a $52.6 \mathrm{~mm}$ diameter cell and the perforation was conducted with a $3 \mathrm{~mm}$ diameter spherical probe and test velocity equal to $1 \mathrm{~mm} / \mathrm{s}$. Puncture strength $(\mathrm{P})$ and the displacement of the probe (D) at break were determined directly from the force displacement curves. Puncture strength value was divided by the thickness of the sample (five random points with a digital caliper rule, Ford) and expressed in N/mm (Sabato et al. 2001). Equation 7 was used to calculate puncture deformation $\left(\Delta \mathrm{l} / \mathrm{1}_{0}\right)$ of the swollen hydrogels, considering that the stress was perfectly distributed along the film at the breaking point (Alves et al. 2011).

$$
\frac{\Delta l}{l_{0}}=\frac{\left[\left(D^{2}+l_{0}^{2}\right)^{1 / 2}-l_{0}\right.}{l_{0}}
$$

\section{STATISTICAL ANALYSIS}

The results are expressed as mean \pm standard error of the mean. Data were subjected to Students t-test using Statistica 7.0 software and the level of significance used was $\mathrm{p}<0.05$.

\section{RESULTS AND DISCUSSION}

Air dried hydrogel (ADH) has a vitreous aspect when compared to the freeze dried hydrogel (FDH) samples, which showed an opaque, whitish appearance. At Figure 1, SEM images from hydrogels surface (FDH-S and ADH-S) and fragile fractures (FDH-F and ADH-F) showed the microstructural modification caused by the drying treatments. ADH sample presented a smooth surface as well as a compact, continuous structure. Cao et al. (2007) noted that the cross-section of native gelatin films presented fibrillary orientation and when gelatin was crosslinked with ferulic acid and tannin acid, an apparent decrease in free volume could be observed. Jiang and Tang (2013) also observed that TGase crosslinking of gelatin resulted in films with a more compact microstructure. Gelatin films produced by Cao et al. (2007) and Jiang and Tang (2013) were dried at room temperature and even the crosslinked films presented fibrillary aspect. Betul et al. (2003) evaluated the effect of drying temperature on wheat gluten films microstructure and observed smoother surfaces when $50^{\circ} \mathrm{C}$ was applied. Denavi et al. (2009) concluded by Scanning and Transmission Electron Microscopy that the drying conditions of soy protein films $\left(70{ }^{\circ} \mathrm{C}\right.$ and $\left.30 \% \mathrm{RH}\right)$ could promote 


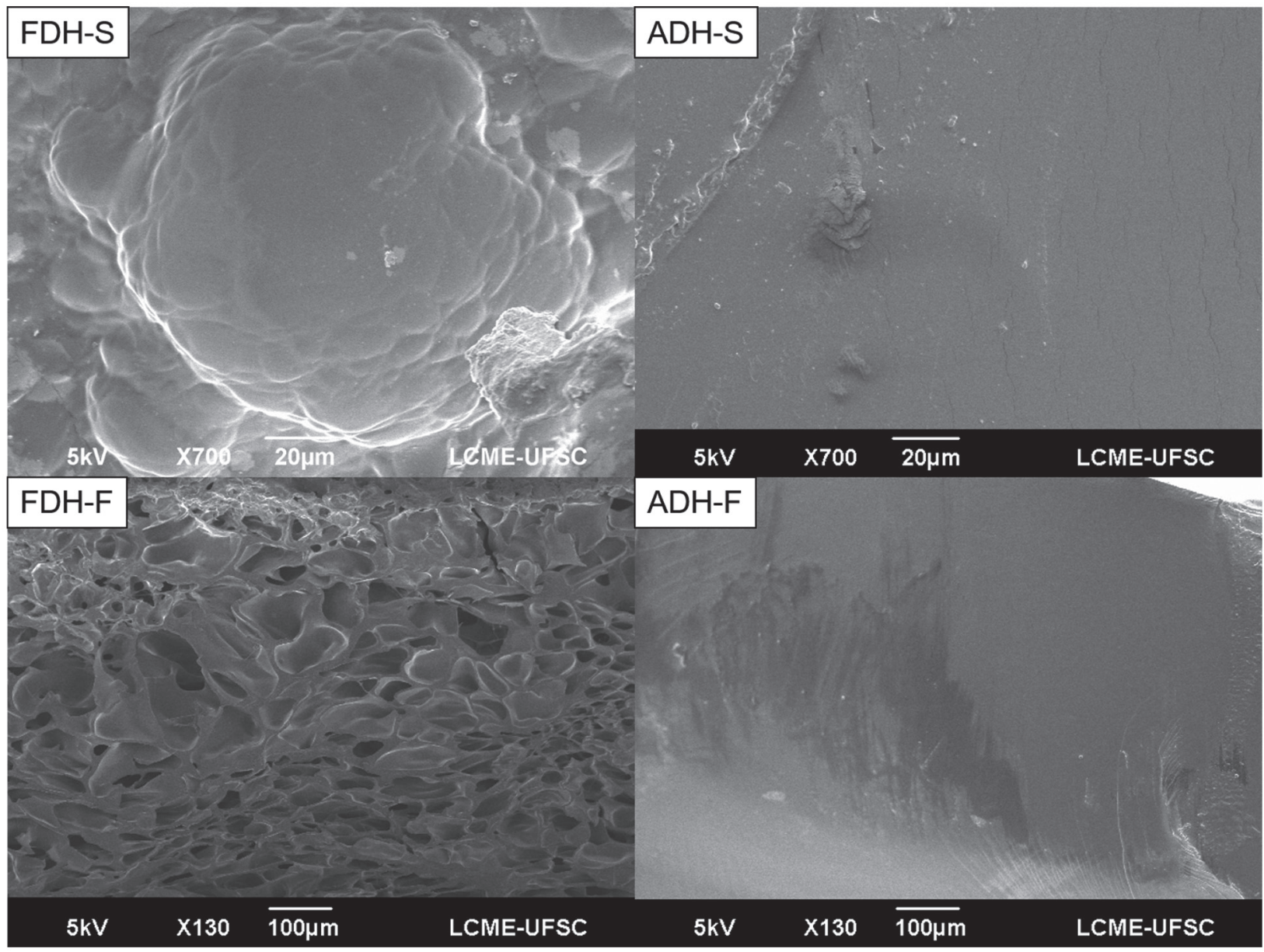

Figure 1 - Scanning Electron Microscopy images of: freeze dried gelatin hydrogel surface (FDH-S) and fragile fracture (FDH-F); air dried hydrogel surface (ADH-S) and fragile fracture (ADH-F). Magnifications: 700x surface and 130x fracture.

the formation of a higher number of hydrophobic interactions within the film structure, consequently a more compact structure. The ADH samples produced at the present work presented a smooth aspect at both surface and fracture suggesting that the drying method influenced the gelatin network conformation and interactions resulting in a smother microstructure.

FDH samples presented a rough surface and internal porous structure with sizes varying from 10 to $150 \mu \mathrm{m}$. During freeze drying, materials are dried by sublimation of ice crystals under vacuum at a temperature below the ice freezing point (Kang et al. 1999). In such cases, pore sizes may be controlled only the size of ice crystals formed during the freezing process. Peng and Chen (2011) commented that the free water in the polymeric solution is frozen causing polymer chains to gather and condense leading to a honeycomb structure after ice sublimation. On the other hand, for the air-drying method, there is more time to water evaporate leading to an equilibrium polymeric chain conformation (Ahmad et al. 2015, Zhang et al. 2013). Risbud et al. (2000) have found pore sizes equal to $39 \mu \mathrm{m}$ in freeze-dried films of glutaraldehyde crosslinked chitosan/polyvinylpyrrolidone.

The equilibrium degree of swelling (EDS), puncture strength and puncture deformation found for the air dried and freeze dried hydrogels are presented in Table I. No significant difference $(p>0.05)$ was 
detected in EDS due to the drying method indicating that final water uptake was the same for both cases disregarding internal materials morphology. Risbud et al. (2000) studied the effect of different $\mathrm{pH}$ on the swelling ratio (relation between swollen and dried hydrogel's weight) of air dried and freeze dried chitosanpolyvinylpyrrolidone hydrogels only during $180 \mathrm{~min}$. Results obtained by these researchers indicate that after 180 min at pH 7 hydrogels reached values of 8 and $2.2\left(\mathrm{~g}_{\text {wet hydrogel }} / \mathrm{g}_{\text {dry hydrogel }}\right)$ for freeze dried and the air dried hydrogels respectively. Probably the hydrogels evaluated at the present work presented the same swelling degree due to the significant larger period of time evaluated.

Mechanical characterization provided that puncture strength for ADH and FDH were statistically equal. Alves et al. (2011) obtained puncture strength values up to $12 \mathrm{~N}$ for gelatin-poly(vinyl alcohol) hydrogels and Sabato et al. (2001) up to $52 \mathrm{~N} / \mathrm{mm}$ for a blend of soy protein isolate and whey protein isolate. It is worth noting that analyses were carried out here with swollen hydrogels, which presented lower resistance due to the relaxation of the crosslinked chains. Puncture deformation (Table I) presented a significant difference $(p<0.05)$ between the treatments as FDH deformed approximately four times more than ADH. Since the crosslinking degree is the same for both samples the effect of the crosslinking extent evaluated by other authors (Johnson et al. 2004) is not worth in this case. Also, in some cases the mechanical performance of hydrogels is more related with chain distribution and entanglement than with the incorporated water content (Lopes and Felisberti 2003). The increase in mechanical strength due to the drying process is important since improving mechanical properties of hydrogels usually comes as at the cost of reducing swelling degree. In the present work it is evident that chain conformation of gelatin is different for FDH and ADH.

TABLE I

Equilibrium degree of swelling (EDS\%), puncture strength $(\mathrm{N})$, puncture deformation $\left(\Delta \mathrm{I} / \mathrm{I}_{0}, \%\right)$ and thermal properties obtained for gelatin hydrogels.

\begin{tabular}{ccccccc}
\hline Treatment & EDS (\%) & $\begin{array}{c}\text { Puncture strength } \\
(\mathbf{N} / \mathbf{m m})\end{array}$ & $\boldsymbol{\Delta l}_{\mathbf{l} / \mathbf{I}_{\mathbf{0}} \mathbf{( \% )}}$ & $\mathbf{T g}\left(\mathbf{(}^{\mathbf{O}} \mathbf{C}\right)$ & $\mathbf{T m}\left({ }^{\mathbf{0}} \mathbf{C}\right)$ & $\boldsymbol{\Delta H}(\mathbf{J} / \mathbf{g})$ \\
\hline Freeze dried (FDH) & $377.41 \pm 12.00$ & $0.545 \pm 0.378$ & $4.85 \pm 0.89$ & 27.03 & 47.40 & 120.75 \\
Air dried (ADH) & $418.06 \pm 26.36$ & $0.749 \pm 0.178$ & $1.29 \pm 0.95$ & 49.15 & 31.56 & 177.78 \\
p-value & 0.917359 & 0.444234 & 0.009019 & - & - & - \\
\hline
\end{tabular}

Kinetics of swelling degree in non enzymatic simulated gastric and intestinal fluids (Figure 2) showed significant differences $(\mathrm{p}<0.05)$ after $180 \mathrm{~min}$ swelling. FDH kept swelling in simulated intestinal fluid while air-dried hydrogel presented the same swelling degree value until $360 \mathrm{~min}$ of analysis. Risbud et al. (2000) have found significant differences between air- and freeze-dried chitosan/PVP blend hydrogels crosslinked with glutaraldehyde. Freeze dried hydrogels exhibited superior $\mathrm{pH}$-dependent swelling properties at lower $\mathrm{pH}$ values, which could be attributed to their porous nature. At the present study, the major dependence was observed for the simulated intestinal fluid which presented $\mathrm{pH}$ equal to 7.4. According to Zhu et al. (2012), gelatin acts as base in acidic medium forming $\mathrm{NH}_{3}^{+}$and $-\mathrm{COOH}$ while proteins become positively charged. In alkaline medium, protein acts as an acid donating $\mathrm{H}^{+}$thus forming $-\mathrm{COO}^{-}$while $-\mathrm{NH}_{2}$ groups become negatively charged. Between $\mathrm{pH} 3$ and 7 both mechanisms are present $\left(\mathrm{NH}_{3}^{+}\right.$and $\left.\mathrm{COO}^{-}\right)$. They observed that in basic medium gelatin hydrogels swelling was higher and concluded that this behavior was due to the presence of the hydrophilic functional groups (mainly COO) in the gelatin structure. Moreover, gelatin hydrogels can be hydrolyzed to form carboxyl groups, which also result in increasing of the swelling ratio. 


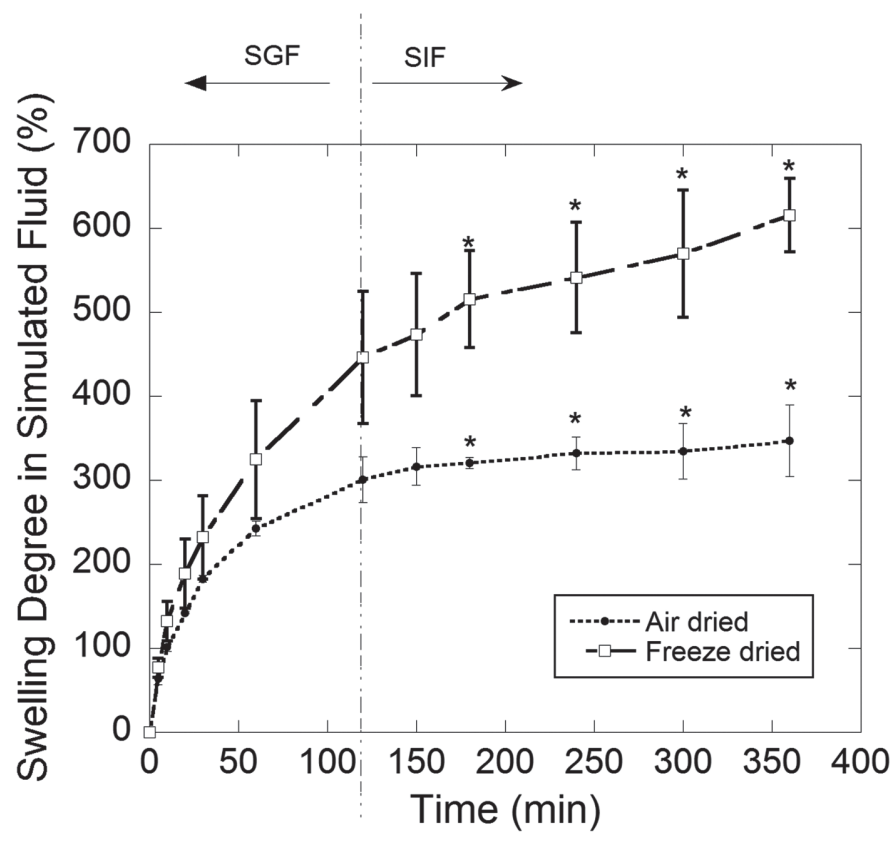

Figure 2 - Swelling degree of the gelatin hydrogels in free enzyme gastric (SGF) and intestinal (SIF) simulated fluids: $(\bullet)$ air-dried (ADH) and $(\square)$ freeze-dried $(\mathrm{FDH})$; *significant difference $(\mathrm{p}<0.05)$.

The higher swelling degree of freeze dried gelatin hydrogel (Figure 2) could be explained by the presence of hydrophilic functional groups (mainly COO-) and by the polymeric network hydrolysis that was favored in the more porous structure of the freeze-dried samples. Larger amounts of unbound water are present at highly swollen hydrogels allowing an improved solute release (Kim et al. 2003). This could be an important characteristic to release entrapped molecules at a higher rate on the intestinal tract.

Thermal characterization of FDH and ADH is presented in Figure 3 and Table I. Glass transition temperature ( $\mathrm{Tg}$ ) values obtained for both cases were lower than pure gelatin. However, it is worth noting that samples were equilibrated in a desiccator with silica during 2 weeks after analysis and the crosslinking degree from both samples did not presented significant difference $(\mathrm{p}>0.05)$. Although gelatin presented a highly hydrophilic character, its glass transition temperature $(\mathrm{Tg})$ in the dry state was $217^{\circ} \mathrm{C}$, but strongly decreases to approximately $0{ }^{\circ} \mathrm{C}$ according to the Fox-Flory equation for water contents up to 25 wt \%. According to An increase in Tg is also expected for high crosslinking degree (Apostolov et al. 1999). According Farris et al. (2011), lower Tg values could be explained by an 'inhibition effect' exerted by the crosslinker, which prevented the recovery of the structurally ordered microcrystalline domains (micro crystallites) leading to a more amorphous final molecular structure. Furthermore, FDH presented lower Tg corroborating the amorphous structure hypothesis since the polymeric matrix remained at the same conformation during the drying step, unlike the ADH. FDH fusion enthalpy was also reduced (Table II) showing a that a more amorphous structure was created during the freeze drying when compared to the air dried sample.

Water absorption data and model parameters for ADH and FDH are presented in Table II and Figure 4. It is possible to observe a fast swelling in the early stages (before $60 \mathrm{~min}$ ) in both cases suggesting that swelling took place following a chain relaxation mechanism (Argin et al. 2014). PeppasSahlin 


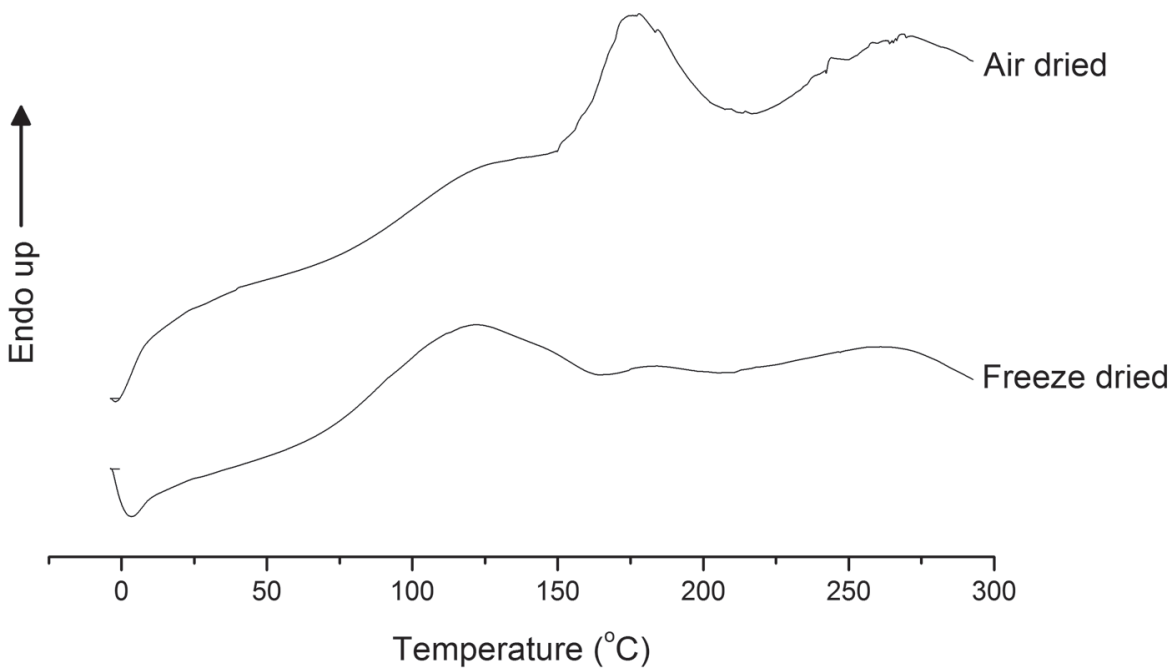

Figure 3 - DSC thermograms of freeze-dried (FDH) and air-dried (ADH) gelatin hydrogels.

TABLE II

Water absorption model parameters for air (ADH) and freeze dried (FDH) gelatin hydrogels using Higuchi, KorsmeyerPeppas, and Peppas-Sahlin Equations.

\begin{tabular}{cccccccccc}
\hline \multirow{2}{*}{ Treatment } & \multicolumn{3}{c}{ Higuchi model } & \multicolumn{3}{c}{ Korsmeyer-Peppas } & \multicolumn{3}{c}{ Peppas-Sahlin } \\
\cline { 2 - 10 } & $\mathrm{k}$ & $\mathrm{R}^{2}$ & $\mathrm{k}$ & $\mathrm{n}$ & $\mathrm{R}^{2}$ & $\mathrm{k}_{\mathrm{r}}$ & $\mathrm{k}_{\mathrm{d}}$ & $\mathrm{m}$ & $\mathrm{R}^{2}$ \\
\hline Freeze dried & 0.0605 & 0.9380 & 0.1641 & 0.3109 & 0.9975 & 0.1428 & -0.000030 & 0.3505 & 0.9994 \\
Air dried & 0.0670 & 0.7646 & 0.2945 & 0.2178 & 0.9904 & 0.2424 & -0.000007 & 0.2765 & 0.9986 \\
\hline
\end{tabular}

$\mathrm{k}^{\prime}\left(\min ^{-0.5}\right)$, Higuchi kinetic constant; $\mathrm{k}\left(\mathrm{min}^{-\mathrm{n}}\right)$, Korsmeyer-Peppas kinetic constant; $\mathrm{n}$ is the release exponent describing the mode of the transport mechanism; $\mathrm{k}_{\mathrm{d}}\left(\mathrm{min}^{-0.43}\right)$, diffusional constant; $\mathrm{k}_{\mathrm{r}}\left(\mathrm{min}^{-0.86}\right)$, relaxational constant; $\mathrm{m}$ is the purely Fickian diffusion exponent for a system of any geometrical shape; $r^{2}$, correlation coefficient.
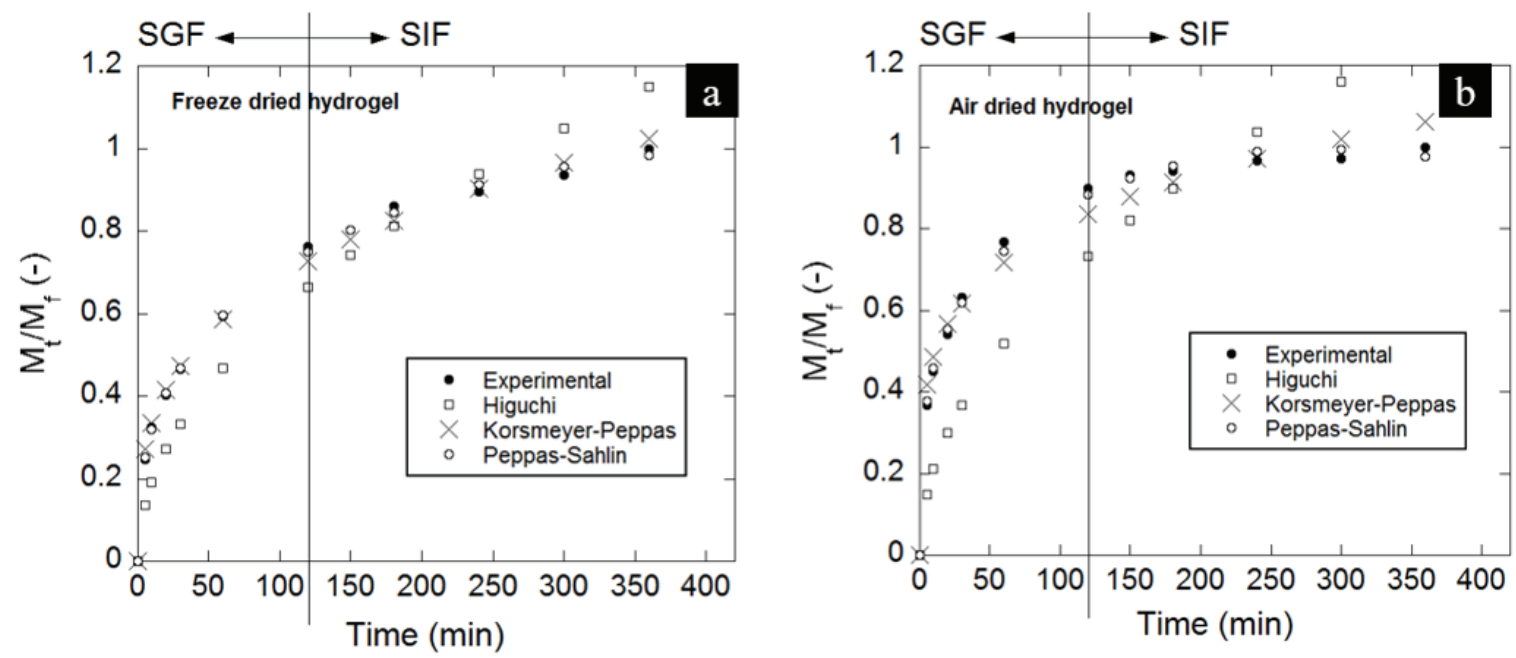

Figure 4 - Water absorption data of gelatin hydrogels (a) freeze-dried (FDH); (b) air-dried (ADH); in simulated gastric fluid (SGF) and simulated intestinal fluid (SIF). Experimental data $(\bullet)$ and modeled data obtained by Higuchi $(\square)$, Korsmeyer-Peppas $(\times)$, and Peppas-Sahlin (०) equations. 
model presented the best fit to the experimental results for both ADH and FDH $\left(\mathrm{R}^{2}=0.9986\right.$ and 0.9994 , respectively). The negative values obtained for $\mathrm{k}_{\mathrm{d}}$ should be interpreted in terms of a relaxation mechanism insignificant compared to the diffusion process. The low $n$ value determined by the Korsmeyer-Peppas equation and the significantly higher values obtained for $\mathrm{k}_{\mathrm{d}}$ compared to $\mathrm{k}_{\mathrm{r}}$ by the Peppas-Sahlin equation indicates that the swelling of gelatin FDH in the simulated intestinal fluid followed a diffusioncontrolled mechanism (Argin et al. 2014). Also, for FDH a good fit to the Higuchi model was achieved. In the case of the ADH the lack of adjustment to Higuchi model suggests that the relaxation mechanism is important at the beginning of swelling process, where water is incorporated to the polymeric matrix leading to the expansion of its structure. These results are in agreement with the morphological characteristics presented at Figure 1. It is wotrh noted that, according to Bajpai et al. (2008), if the glass transition temperature of the polymer is below the experimental temperature, the polymer will be in the rubbery state and polymer chains may have high mobility allowing fast penetration of the solvent into the hydrogel matrix, resulting in a Fickian diffusion mechanism. This is the case for the freeze dried hydrogel since water absortion data was obtained at $37^{\circ} \mathrm{C}$ while its $\mathrm{Tg}$ was $27^{\circ} \mathrm{C}$.

\section{CONCLUSIONS}

Enzymatically crosslinked gelatin hydrogels were dried by freeze drying and air drying. They presented signifficant differences on their thermal characteristics and swelling behavior in non enzymatic simulated gastric and intestinal fluids due to the changes which may be atributed to different polymeric chain conformation caused by the drying method. Freezedried hydrogel presented porous structure, amorphous chain conformation and a lower glass transition temperature leading to a Fickian difusion behaviour during swelling. This conclusion was confirmed by the Peppas-Sahlin model adjustment. On the other hand, air dried hydrogels presented a compact, non porous structure and higher glass transition temperature. These results suggests that the same gelatin hydrogel may be suitable to distinct applications depending on the drying process used.

\section{ACKNOWLEDGMENTS}

Authors thank to Conselho Nacional de Desenvolvimento Científico e Tecnológico (MCTI/CNPq N 14/2014, 447768/2014-0) and to Fundação Araucária de Apoio ao Desenvolvimento Científico e Tecnológico do Paraná (Bolsa do Convênio 117/15) for the financial support.

\section{REFERENCES}

AHMAD M, HANI NM, NIRMAL NP, FAZIAL FF, MOHTAR NF AND ROMLI SR. 2015. Optical and thermo-mechanical properties of composite films based on fish gelatin/rice flour fabricated by casting technique. Progr Org Coat 84: 115-127.

ALVES PMA, CARVALHO RA, MORAES ICF, LUCIANO CG, BITTANTE AMQB AND SOBRAL PJA. 2011. Food Hydrocolloids Development of films based on blends of gelatin and poly (vinyl alcohol) cross linked with glutaraldehyde. Food Hydrocolloid 25(7): 1751-1757.

APOSTOLOV AA, FAKIROV S, VASSILEVA E, PATIL RD AND MARK JE. 1999. DSC and TGA Studies of the Behavior of Water in Native and Crosslinked Gelatin. J App Polym Sci 71: 465-470.

ARGIN S, KOFINAS P AND LO YM. 2014. The cell release kinetics and the swelling behavior of physically crosslinked xanthanchitosan hydrogels in simulated gastrointestinal conditions. Food Hydrocolloid 40: 138-144.

BAJPAI AK, SHUKLA SK, BHANU S AND KANKANE S. 2008. Responsive polymers in controlled drug delivery. Progr Polym Sci 33(11): 1088-1118. 
BETUL SK, BAKIR U, YILMAZ L AND AKKAS N. 2003. Drying Temperature and Relative Humidity Effects on Wheat Gluten Film Properties. J Agr Food Chem 51: 964-968.

CAO N, FU Y AND HE J. 2007. Mechanical properties of gelatin films cross-linked, respectively, by ferulic acid and tannin acid. Food Hydrocolloid 21(4): 575-584.

CARVALHO RA DE AND GROSSO CRF. 2006. Efeito do tratamento térmico e enzimático nas propriedades de filmes de gelatina. Cienc Tecnol Alim 26(3): 495-501.

CHAMBI H AND GROSSO C. 2006. Edible films produced with gelatin and casein cross-linked with transglutaminase. Food Res Int 39(4): 458-466.

CHUNG C, DEGNER B AND JULIAN D. 2014. Reduced calorie emulsion-based foods: Protein microparticles and dietary fiber as fat replacers. Food Res Int 64: 664-676.

DENAVI G, TAPIA-BLÁCIDO DR, AÑÓN MC, SOBRAL PJA, MAURI AN AND MENEGALLI FC. 2009. Effects of drying conditions on some physical properties of soy protein films. J Food Engin 90: 341-349.

DEVI N AND MAJI TK. 2010. Genipin crosslinked microcapsules of gelatin A and $\kappa$-carrageenan polyelectrolyte complex for encapsulation of Neem (Azadirachta Indica A.Juss.) seed oil. Polym Bul 65(4): 347-362.

DÍAZ-BANDERA D, VILLANUEVA-CARVAJAL A, DUBLÁN-GARCÍA O, QUINTERO-SALAZAR B AND DOMINGUEZLOPEZ A. 2013. Original article Release kinetics of antioxidant compounds from Hibiscus sabdariffa L. encapsulated in gelatin beads and coated with sodium alginate. Int J Food Sci Tech 48: 2150-2158.

DONG ZJ, XIA SQ, HUA S, HAYAT K, ZHANG XM AND XU SY. 2008. Optimization of cross-linking parameters during production of transglutaminase-hardened spherical multinuclear microcapsules by complex coacervation. Colloid Surface B 3(1): 41-47.

EINERSON NJ, STEVENS KR AND JOHN W. 2002. Synthesis and physicochemical analysis of gelatin-based hydrogels for drug carrier matrices. Biomaterials 24: 509-523.

FARRIS S, SCHAICH KM, LIU L, COOKE PH, PIERGIOVANNI L AND YAM KL. 2011. Gelatin-pectin composite films from polyion-complex hydrogels. Food Hydrocolloid 25(1): 61-70.

HEIDEBACH T, FÖRST P AND KULOZIK U. 2009. Transglutaminase-induced caseinate gelation for the microencapsulation of probiotic cells. Int Dairy J 19(2): 77-84.

JIANG Y AND TANG CH. 2013. Effects of transglutaminase on sorption, mechanical and moisture-related properties of gelatin films. Food Sci Tech Int 19(2): 99-108.

JOHNSON BD, BEEBE DJ AND CRONE WC. 2004. Effects of swelling on the mechanical properties of a pH-sensitive hydrogel for use in microfluidic devices. Mat Sci Engin C 24: 575-581.

KANG H, TABATA Y AND IKADA Y. 1999. Fabrication of porous gelatin scaffolds for tissue engineering. Biomaterials 20: 2-7.

KHAN SA AND SCHNEIDER M. 2013. Improvement of nanoprecipitation technique for preparation of gelatin nanoparticles and potential macromolecular drug loading. Macromol Biosci 13(4): 455-463.

KIM B, FLAMME KLA AND PEPPAS NA. 2003. Dynamic Swelling Behavior of pH-Sensitive Anionic Hydrogels Used for Protein Delivery. J App Polym Sci 89: 1606-1613.

KOO SY, CHA KH, SONG DG, CHUNG D AND PAN CH. 2014. Microencapsulation of peppermint oil in an alginate-pectin matrix using a coaxial electrospray system. Int J Food Sci Tech 49(3): 733-739.

LIM LT, MINE Y AND TUNG MA. 1999. Barrier and Tensile Properties of Transglutaminase Cross-linked Gelatin Films as Affected by Relative Humidity, Temperature, and Glycerol Content. J Food Sci 64(4): 616-622.

LOPES CMA AND FELISBERTI MI. 2003. Mechanical behaviour and biocompatibility of poly (1-vinyl-2-pyrrolidinone)-gelatin IPN hydrogels. Biomaterials 24: 1279-1284.

MANZOCCO L, VALOPPI F AND NICOLI MC. 2013. Effect of palm oil replacement with monoglyceride organogel and hydrogel on sweet bread properties. Food Res Int 51: 596-602.

MCCLEMENTS DJ, DECKER EA, PARK Y AND WEISS J. 2009. Structural Design Principles for Delivery of Bioactive Components in Nutraceuticals and Functional Foods. Cr Rev Food Sci 49(6): 577-606.

PAL K, BANTHIA AK AND MAJUMDAR DK. 2007. Preparation and characterization of polyvinyl alcohol-gelatin hydrogel membranes for biomedical applications. AAPS PharmSciTech 8(1): E1-E5.

PENG Z AND CHEN F. 2011. Hydroxyethyl Cellulose-Based Hydrogels with Various Pore Sizes Prepared by Freeze-Drying. J Macromol Sci 50(2): 340-349.

PEREIRA JR VA, DE ARRUDA INQ AND STEFANI R. 2015. Active chitosan / PVA films with anthocyanins from Brassica oleraceae (Red Cabbage) as Time e Temperature Indicators for application in intelligent food packaging. Food Hydrocolloid 43: $180-188$. 
PRATA AS, ZANIN MHA, RÉ MI AND GROSSO CRF. 2008. Release properties of chemical and enzymatic crosslinked gelatingum Arabic microparticles containing a fluorescent probe plus vetiver essential oil. Colloid Surface B 67(2): 171-178.

RISBUD MV, HARDIKAR AA, BHAT SV AND BHONDE RR. 2000. Hydrogels as controlled release system for antibiotic delivery. J Control Release 68: 23-30.

SABATO SF, OUATTARA B, YU H, D’APRANO G, LE TIEN C, MATEESCU MA AND LACROIX M. 2001. Mechanical and Barrier Properties of Cross- Linked Soy and Whey Protein Based Films. J Agr Food Chem 49: 1397-1403.

SHALABY WSW, PECK GE AND PARK K. 1991. Release of dextromethorphan hydrobromide from freeze-dried enzymedegradable hydrogels. J Control Release 16: 355-363.

SHEWAN HM AND STOKES JR. 2013. Review of techniques to manufacture micro-hydrogel particles for the food industry and their applications. J Food Engin 119(4): 781-792.

THE UNITED STATE PHARMACOPEIA. 1999. US Pharmacopeial Convention, Inc. (I. US Pharmacopeial Convention, Ed.) (24th ed.). Rockvile, MD.

WANG T, ZHU XK, XUE XT AND WU DY. 2012. Hydrogel sheets of chitosan, honey and gelatin as burn wound dressings. Carbohyd Polym 88(1): 75-83.

ZHANG N, LIU H, YU L, LIU X, ZHANG L, CHEN L AND SHANKS R. 2013. Developing gelatin - starch blends for use as capsule materials. Carbohyd Polym 92(1): 455-461.

ZHU D, JIN L, WANG Y AND REN H. 2012. Swelling behavior of gelatin-based hydrogel cross-linked with microbial transglutaminase. J Aqeic 63: 11-20. 